\title{
Preventing Invasive Pneumococcal Disease in Children
}

\author{
Richard D. Clover, MD
}

Streptococcus pneumoniae is a major bacterial cause of sepsis, meningitis, and otitis media in infants and young children. In 1999, the Active Bacterial Core Surveillance Network reported a rate of invasive pneumococcal disease of 165.7 per 100,000 in children younger than 1 year old and a rate of 205.4 per 100,000 for 1-year-old children. These rates were the highest of any other age group. Invasive pneumococcal disease occurs significantly more in African Americans, Native Americans, and Alaskan natives than in whites and in children who have certain conditions, including sickle cell disease, asplenism, and human immunodeficiency virus infection. ${ }^{1}$

In February 2000, a 7-valent pneumococcal conjugate vaccine (PCV 7) (Prevnar) was licensed for use in infants and children. The American Academy of Family Physicians, the American Academy of Pediatrics, and the Advisory Committee on Immunization Practices of the Centers for Disease Control and Prevention recommended that this vaccine be used for all children aged 2 through 23 months and for children aged 24 through 59 months who have an increased risk of pneumococcal disease (eg, children with sickle cell disease, human immunodeficiency virus infection, other immunocompromising or chronic medical conditions). The vaccine should also be considered for all other children aged 24 to 59 months, with priority given to (1) children age 24 to 35 months, (2) children who are of native Alaskan, Native American, and African American descent, and (3) children who attend group day-care centers. ${ }^{2}$ In this issue of the Fournal of the American Board of Family Practice,

Submitted 17 July 2003

From the School of Public Health and Information Sciences, University of Louisville. Address correspondence to Richard D. Clover, MD, School of Public Health and Information Sciences, University of Louisville, 555 S. Floyd Street, Suite 4026, Louisville, KY 40202 (e-mail: rclover@ louisville.edu).
Davis et $\mathrm{al}^{3}$ report a 1 -year uptake of the use of this vaccine and adherence to these recommendations.

The authors report that family physicians' adherence to these recommendations for their patients under 2 years old was less than that of pediatricians (68 vs 99 , respectively). Family physicians who followed these recommendations were more likely to have been in a larger practice, had a larger number of infants in their practices, and had higher rates of African American children and Medicaid beneficiaries in their practices. Even though the authors noted no differences among family physicians working in states with different vaccine financing strategies for pneumococcal conjugate vaccine, the cost of purchasing the vaccine may have influenced their findings, especially because lack of insurance reimbursement was the most commonly cited factor among physicians who were not using PCV 7. When considering the variety of services that family physicians provide, cost of a service or procedure may be a predictor in a family physician's decision to provide that service. If the family physician's practice has a high volume of patients who will benefit from that service, the physician may be more likely to provide that service. The practice characteristics that were identified are consistent with the above assumption. However, a physician's decision to provide or not to provide pneumococcal vaccine in his/her office should not prevent advising the patient of the benefit of immunization and an appropriate referral.

The finding that some physicians express concern about administering more than four injections at one visit has been reported in previous studies. ${ }^{4}$ With the potential for additional vaccines being added to the childhood schedule, this concern will continue. This finding supports the need for combination vaccines to help reduce the number of injections that need to be administered at any given visit.

A physician's lack of knowledge of the true benefit and risk of the vaccine and the at risk groups for 
pneumococcal conjugate vaccine is noteworthy. Vaccination rates of many of the current license vaccines that target at-risk groups are lower than those that have the universal age-based recommendations. Several studies have recently been published that demonstrate a physician's knowledge deficit as to efficacy of vaccines and appropriate indications and contraindications. ${ }^{5-9}$ In addition, Cohen et al ${ }^{10}$ recently reported that childhood vaccine providers have substantial knowledge deficits of recommended catch-up schedules for normal childhood immunizations. Although physician education to improve knowledge deficits is important, it requires a substantial period of time to reach all clinicians using standard methods. These findings argue strongly for the need of electronic immunization registries with decision support rules that may be updated rapidly to assist physicians in the appropriate administration of vaccines. As the number of vaccines in the routine childhood immunization schedule and vaccines targeted for atrisk groups increases, the argument for electronic decision support becomes even more persuasive.

\section{References}

1. Centers for Disease Control and Prevention. Active Bacterial Core Surveillance program. Available at: URL: http://www.cdc.gov/ncidod/dbmd/abcs

2. Advisory Committee on Immunization Practices. Preventing pneumococcal disease among infants and young children. Recommendations of the Advisory Committee on Immunization Practices (ACIP). MMWR Recomm Rep 2000;49:1-35.
3. Davis MM, Ndiaye SM, Freed GL, Clark SJ. Oneyear uptake of pneumococcal conjugate vaccine: a national survey of family physicians and pediatricians. J Am Board Fam Pract 2003;16:363-71.

4. Woodin KA, Rodewalk LE, Humiston SG, Carges MS, Schaffer SJ, Szilagyi PG. Physician and parent opinions: are children becoming pincushions from immunizations? Arch Pediatr Adolesc Med 1995; 149:845-9.

5. Zimmerman RK, Mieczkowski TA, Mainzer HM, Medsger AR, Nowalk MP. Understanding physician agreement with varicella immunization guidelines. Prev Med 2002;35:135-42.

6. Zimmerman RK, Giebink GS, Street HB, Janosky JE. Knowledge and attitudes of Minnesota primary care physicians about barriers to measles and pertussis immunization. J Am Board Fam Pract 1995;8: 270-7.

7. Nichol KL, Zimmerman R. Generalist and subspecialist physicians' knowledge, attitudes, and practices regarding influenza and pneumococcal vaccinations for elderly and other high-risk patients: a nationwide survey. Arch Intern Med 2001;161:2702-8.

8. Zimmerman RK, Bradford BJ, Janosky JE, Mieczkowski TA, DeSensi E, Grufferman S. Barriers to measles and pertussis immunization: the knowledge and attitudes of Pennsylvania primary care physicians. Am J Prev Med 1997;13:89-97.

9. Ehresmann KR, Mills WA, Loewenson PR, Moore $\mathrm{KA}$. Attitudes and practices regarding varicella vaccination among physicians in Minnesota: implications for public health and provider education. Am J Public Health 2000;90(12):1917-20.

10. Cohen NJ, Lauderdale DS, Shete PB, Seal JB, Daum RS. Physician knowledge of catch-up regimens and contraindications for childhood immunizations. Pediatrics 2003;111:925-32. 